\title{
Effect of Low Calorie Diet and Controlled Fasting on Insulin Sensitivity and Glucose Metabolism in Obese Patients With Type 1 Diabetes Mellitus
}

\author{
F. MUSIL ${ }^{1}$, A. ŠMAHELOVÁ ${ }^{1}$, V. BLÁHA ${ }^{1}$, R. HYŠPLER $^{2}$, A. TICHÁ ${ }^{2}$, J. LESNÁ $^{1}$, \\ Z. ZADÁK ${ }^{2}$, L. SOBOTKA ${ }^{1}$
}

${ }^{1}$ Department of Metabolic Care and Gerontology, ${ }^{2}$ Department of Research and Development, Faculty of Medicine, Charles University and University Hospital, Hradec Králové, Czech Republic

Received April 30, 2012

Accepted November 9, 2012

On-line March 14, 2013

\begin{abstract}
Summary
Obesity in T1DM patients is associated with the components of metabolic syndrome. The influence of controlled fasting and low calorie diet (LCD) on insulin sensitivity and glucose metabolism was studied in 14 obese patients with type 1 diabetes mellitus (T1DM) (42.6 \pm 9.4 years, BMI $\left.32.4 \pm 2.1 \quad \mathrm{~kg} \mathrm{~m}^{-2}\right)$. Insulin sensitivity in obese T1DM patients was measured using a hyperinsulinemic-euglycemic clamp before fasting, immediately after 7 days of fasting, and after 21 days of LCD. Glucose oxidation and non-oxidative glucose disposal were measured before and during the clamp by indirect calorimetry. In the control group of 13 of non-obese T1DM patients (36.9 \pm 13.9 years, BMI $22.6 \pm 2.1 \mathrm{~kg} \mathrm{~m}^{-2}$ ), only one hyperinsulinemiceuglycemic clamp was performed. Obese T1DM patients lost $6.1 \pm 1.1 \mathrm{~kg}$ after fasting and maintained reduction in body weight after 21 days of LCD. Fasting transiently reduced insulinmediated glucose disposal in the clamp (from $9.69 \pm 1.48$ to $6.78 \pm 1.21 \mathrm{mg} \mathrm{min}^{-1} \mathrm{~kg}^{-1}, \mathrm{P}<0.001$ ). This was caused by reduced glucose oxidation after the fasting period (from $2.81 \pm 0.52$ to $\left.0.88 \pm 0.98 \mathrm{mg} \mathrm{min}^{-1} \mathrm{~kg}^{-1}, \mathrm{P}<0.001\right)$. We conclude that one week of fasting transiently decreased insulin-mediated glucose disposal in T1DM patients. This was caused by reduced glucose oxidation.
\end{abstract}

\section{Key words}

Type 1 diabetes mellitus • Obesity • Fasting • Low calorie diet • Insulin sensitivity

\section{Corresponding author}

František Musil, Department of Metabolic Care and Gerontology, University Hospital Hradec Králové and Medical Faculty Charles
University in Hradec Králové, Sokolská 581, 50005 Hradec Králové, Czech Republic. Fax: $420495832001 . \quad$ E-mail: musil@fnhk.cz

\section{Introduction}

The prevalence of obesity in T1DM patients is growing and is associated with the components of metabolic syndrome and cardiometabolic risk (Libman et al. 2003, Szadkowska et al. 2009, van Vliet et al. 2010). The clinical significance of obesity in T1DM patients is associated with higher incidence of vascular disease and related complications (Chillarón et al. 2009, Kilpatrick et al. 2007, Yip et al. 1993).

Obesity can elicit insulin resistance and contribute to metabolic syndrome (the pathophysiology of which is based on insulin resistance) in genetically susceptible individuals. Studies suggest that the increase in body mass index (BMI) and the consequent insulin resistance (IR) may accelerate the $\beta$-cell destruction process in individuals predisposed to T1DM, due to the release of obesity-related cytokines that show inflammatory and/or immunomodulatory properties (Aldhahi and Hamdy 2003), triggering diabetes. The IR, autoimmunity and apoptosis of the $\beta$-cells constitute the three factors of the so-called "accelerator hypothesis", proposed by Wilkin (2001).

A recent study has demonstrated that about $15 \%$ of people with T1DM have metabolic syndrome as defined by the WHO criteria (McGill et al. 2008). This 
finding implies that T1DM subjects have the same risk of metabolic syndrome as the non-diabetic population from which they are derived (Alexander et al. 2003). The relation between obesity and metabolic syndrome may explain the greater risk of micro- and macrovascular disease in obese T1DM patients.

Intensive insulin therapy, which is now widely used to treat T1DM, on the one hand prevents microvascular and macrovascular complications associated with poor glycemic control, but on the other hand is associated with an increase in body weight (DCCT Research Group 1995). Insulin stimulates lipogenesis, inhibits protein catabolism, and slows basal metabolism. The classically normal-weight or underweight phenotype of T1DM individuals is thus changing. In a follow-up over 18 years of 589 subjects from the cohort of childhood-onset T1DM in the Pittsburgh Epidemiology of Diabetes Complications Study (EDC), it was found that there was an increase in the prevalence of overweight by $47 \%$ (from $28.6 \%$ at baseline to $42 \%$ ) and of obesity by sevenfold (from $3.4 \%$ at baseline to $22.7 \%$ ), concomitantly with the highest prevalence of intensive insulin therapy $-7 \%$ at baseline and $82 \%$ after 18 years were on intensive insulin therapy ( $\geq 3$ insulin injections per day or on insulin pump) (Conway et al. 2010).

Reduction of body weight in obese T1DM patients is difficult and is associated with an increase in the frequency of hypoglycemia (Jacobsen et al. 2009). Adjustments to insulin dose and carbohydrate intake are necessary to reduce the risk of hypoglycemia during body weight reduction (Chokkalingam et al. 2007). Patients need to be active with their diabetes management to accommodate a reduction diet and planned exercise (Kemmer 1992). Controlled fasting in a hospital setting with subsequent home low calorie diet can be a method of choice in the treatment of obesity in patients who were not previously able to reduce their body weight. In a group of obese patients with T2DM, previous research has shown a decrease in insulin sensitivity after fasting (Duška et al. 2005). The effect on insulin sensitivity of fasting in obese T1DM patients has not yet been studied. The aim of our study was to explore the influence on insulin sensitivity of 7 days of fasting followed by 21 days of low calorie diet in obese patients with T1DM. We used a hyperinsulinemic-euglycemic clamp method with two levels of hyperinsulinemia, combined with indirect calorimetry performed before and after the periods of fasting and low calorie diet.

\section{Materials and Methods}

\section{Subjects}

We recruited 14 obese, C-peptide-negative patients with $\mathrm{T} 1 \mathrm{DM}(9 \mathrm{M}+5 \mathrm{~F}$, aged $42.6 \pm 9.4$ years, height $1.74 \pm 0.07 \mathrm{~m}$, weight $97.4 \pm 11.8 \mathrm{~kg}$, BMI $32.4 \pm 2.1$ $\mathrm{kg} \mathrm{m}^{-2}$ ). The mean duration of diabetes was $19.6 \pm 12.5$ years. Four patients were on a multiple daily injections insulin regimen, and 10 were on continuous subcutaneous insulin infusion therapy. Patients had no history of cardiovascular disease, chronic renal failure, or other chronic conditions that would preclude the ability to fast for 7 days. Six obese T1DM patients had history of nonproliferative retinopathy, four patients had history of sensory neuropathy, and three patients had history of microalbuminuria. Arterial hypertension was present in 10 obese T1DM patients. Two obese T1DM patients had history of hyperlipidemia and were treated with lipidlowering agents. Metabolic syndrome defined according to criteria for clinical diagnosis of the metabolic syndrome (Alberti et al. 2009) was present in 10 obese T1DM patients. Controls: We recruited 13 non-obese Cpeptide-negative patients with T1DM $(8 \mathrm{M}+5 \mathrm{~F}$, aged $36.9 \pm 13.9$ years, height $1.76 \pm 0.11 \mathrm{~m}$, weight $69.4 \pm 10.1$ $\mathrm{kg}$, BMI $22.6 \pm 2.1 \mathrm{~kg} \mathrm{~m}^{-2}$ ). The mean duration of diabetes among the non-obese T1DM patients was $11.8 \pm 6.0$ years. Four non-obese patients were on a multiple daily injections insulin regimen, and nine were on continuous subcutaneous insulin infusion therapy. Non-obese T1DM patients had no history of cardiovascular disease or chronic renal failure. Six non-obese T1DM patients had history of nonproliferative retinopathy, four non-obese T1DM patients had history of sensory neuropathy, and three non-obese T1DM patients had history of microalbuminuria. Arterial hypertension was present in four non-obese T1DM patients. Three non-obese T1DM patients had history of hyperlipidemia and were treated with lipid-lowering agents. Metabolic syndrome defined according to criteria for clinical diagnosis of the metabolic syndrome (Alberti et al. 2009) was present in 2 non-obese T1DM patients. There was no significant difference between the patient groups in age, duration of diabetes, or glycated hemoglobin. Written informed consent was obtained from all patients. The study was approved by the local ethics committee.

\section{Study design}

Two days prior to the beginning of the fasting period, the patients were admitted to the diabetes ward 
and placed on a standardized diabetic diet containing $225 \mathrm{~g}$ of carbohydrates and $7400 \mathrm{~kJ}$. One day prior to the beginning of fasting we performed a hyperinsulinemiceuglycemic clamp. After the clamp, patients fasted for 7 days. During the fasting period, patients were only allowed to drink water or sugar-free beverages. Patients were supplemented with potassium $(40 \mathrm{mmol} / \mathrm{day})$, ascorbic acid (100 mg/day) and vitamin B complex (thiamine $15 \mathrm{mg} /$ day, riboflavin $15 \mathrm{mg} /$ day, pyridoxine $10 \mathrm{mg} /$ day, niacin $50 \mathrm{mg} /$ day). Patients received only a basal insulin dose. The dose of basal insulin was changed according to the glycemia. $\beta$-Hydroxybutyrate concentration was measured together with glycemia using blood from a fingerprick test and analyzed by a bedside analyzer, the Precision PCx (Abbott Laboratories, Abbot Park, USA). $\beta$-Hydroxybutyrate concentration was measured only during the fasting period. On the eighth day of the testing period, we repeated the hyperinsulinemic-euglycemic clamp, after which patients started with a standardized low calorie diabetic diet containing $150 \mathrm{~g}$ of carbohydrates and $5000 \mathrm{~kJ}$. Twentyone days after the start of the LCD period, patients were admitted to the diabetes ward again, and the third hyperinsulinemic-euglycemic clamp was performed. In the group of non-obese T1DM patients, only one hyperinsulinemic-euglycemic clamp was performed.

\section{Hyperinsulinemic-euglycemic clamp}

All studies were performed after an 8- to 10hour overnight fast. The two-step hyperinsulinemiceuglycemic clamp, lasting 6 hours (period 1: 0 to $120 \mathrm{~min}$; period 2: 120 to $360 \mathrm{~min}$ ) was conducted as previously described (DeFronzo et al. 1979). Briefly, a Teflon cannula was inserted into the left antecubital vein for infusion of all test substances. A second cannula was inserted in a retrograde fashion into a wrist vein of the same hand for blood sampling, and the hand was placed in a heated $\left(45^{\circ} \mathrm{C}\right)$ cover to achieve venous blood arterialization. A stepwise primed-continuous infusion ( 1 and $10 \mathrm{mU} / \mathrm{kg} / \mathrm{min}$ of Humulin R, Eli Lilly, Indianapolis, USA) was administered to acutely raise and maintain the plasma concentration of insulin. Decreases in serum potassium concentrations during insulin infusion were prevented by co-infusion of potassium chloride with glucose $\left(30 \mathrm{mmol} \mathrm{K}^{+}\right.$per liter of $20 \%$ glucose). Plasma glucose concentrations during the clamp were maintained at $5 \mathrm{mmol} / \mathrm{l}$ by continuous infusion of $20 \%$ glucose.
Blood sampling during clamp procedure

Arterialized blood plasma glucose concentrations were determined every 5 to $10 \mathrm{~min}$. Blood samples were collected at the baseline and each hour during the clamp procedure to determine immunoreactive insulin and free fatty acids (FFA). Blood samples $(5 \mathrm{ml})$ were collected into a tube with potassium ethylenediaminetetraacetic acid $(2 \mathrm{mg} / \mathrm{ml})$. Samples were kept on ice for $3 \mathrm{~min}$, then immediately centrifuged at $4{ }^{\circ} \mathrm{C}$ and 2,500 rcf. Plasma was separated and stored at $-20{ }^{\circ} \mathrm{C}$. Hepatic glucose production was not measured in this study, but this is known to decrease by more than $90 \%$ at insulin levels $>50 \mu \mathrm{U} / \mathrm{ml}$ in healthy men (DeFronzo et al. 1979). Thus, the total amount of glucose infused was a measure of the glucose metabolized by all cells of the body during clamp studies. Calculations of substrate oxidation were made using standard equations (Ferrannini 1988). Insulin action was estimated as glucose disposal (M) calculated at minute 80 to minute 120 (Msubmax) and between 320 and 360 minutes (Mmax). Non-oxidative glucose disposal was calculated by subtracting the rate of glucose oxidation from $\mathrm{M}$. Protein oxidation was calculated by measurement of urinary urea nitrogen excretion during the clamp procedure.

\section{Indirect calorimetry}

We used a ventilated canopy system (VMAX, Sensormedics, Anaheim, USA). Gas exchange measurements were taken during a $30-\mathrm{min}$ basal period and during the final 30-min periods of the two insulininfusion steps. Patients relaxed in the supine position for at least $15 \mathrm{~min}$ before each measurement, which was performed in a thermally comfortable environment for at least $30 \mathrm{~min}$ or until a steady state was reached. Subjects were familiarized with the canopy so that they would not feel suffocation.

\section{Body composition monitor}

Bioimpedance spectroscopy (Fresenius Medical Care, Bad Homburg, Germany) was used to determine body composition. Body composition fat $(\mathrm{kg})$, relative fat $(\%)$, lean tissue mass $(\mathrm{kg})$, and relative lean tissue mass (\%) were determined before the initiation of every hyperinsulinemic-euglycemic clamp.

\section{Analytical methods}

Basic biochemical parameters characterizing their overall condition were monitored in the patients; 
mineralogram, kidney function, urea, creatinine, uric acid, bilirubin, transaminases, and basic lipid metabolism (Modular Analytics, Roche, Basel, Switzerland). The stated parameters were monitored before and after 7 days of starvation and 21 days thereafter. Glycemia during hospitalization or during clamps was determined by glucose-oxidase method by a bedside analyzer Precision PCx (Abbott Laboratories, Abbot Park, USA). Acid-base balance was measured using Stat Profile, Critical Care Xpress (Nova Biomedical, Waltham, USA). Immunoreactive insulin was determined by radioimmunoassay using an Insulin IRMA kit (Immunotech, Prague, Czech Republic). Measurement of glycated hemoglobin was accomplished using liquid chromatography on a Variant Testing System (Bio-Rad Laboratories, Montreal, Canada). Free fatty acids were analyzed by FFA-HR kit (Wako chemicals $\mathrm{GmbH}$, Neuss, Germany) using a UV-VIS spectrophotometer Shimadzu Pharma Spec 1700 UV Probe (Kyoto, Japan). Urinary urea nitrogen excretion was evaluated to calculate protein oxidation. Urinary collections during the clamp were divided into the basal period ( -120 to $0 \mathrm{~min}$ ), period 1 ( 0 to $120 \mathrm{~min}$ ), and period 2 (120 to $360 \mathrm{~min}$ ).

\section{Statistical methods}

The numerical data were tested according to distribution. If a normal distribution was detected, the Ttest and ANOVA were used. The dynamic changes in the group of obese T1DM patients were evaluated using ANOVA for repeated measures (RM), and comparison with controls was evaluated using unpaired T-test. If the distribution of data was non-normal, non-parametric tests were applied: Mann Whitney test and ANOVA on ranks. For correlation analysis, Pearson's correlation coefficient (R) and the associated $\mathrm{p}$ value were calculated. The statistical significance was determined based on a probability level of less than 0.05. Statistical evaluation was done using Sigmastat (Systat Software, USA). All data are expressed as means \pm SD unless otherwise indicated.

Table 1. Clinical and biochemical changes during fasting and LCD period.

\begin{tabular}{|c|c|c|c|c|}
\hline $\begin{array}{l}\text { Obese T1DM } \\
(n=14)\end{array}$ & Before fasting & After fasting & $\begin{array}{l}\text { After } 21 \text { days } \\
\text { of } L C D\end{array}$ & $\begin{array}{c}\text { Controls } \\
(n=13)\end{array}$ \\
\hline Body mass index $\left(\mathrm{kg} \mathrm{m}^{-2}\right)$ & $32.3 \pm 2.1^{\#}$ & $30.4 \pm 1.8^{* *}$ & $30.4 \pm 1.9 * *$ & $22.7 \pm 2.07$ \\
\hline Waist circumference (cm) & $105.5 \pm 9.3^{\#}$ & $98.2 \pm 7.9 * *$ & $98.0 \pm 7.8 * *$ & $80.7 \pm 7.5$ \\
\hline Daily insulin dose (units) & $49.0 \pm 13.4$ & $14.2 \pm 8.9 * *(a)$ & $30.4 \pm 1.9 * *$ & $52.0 \pm 15.4$ \\
\hline $\begin{array}{l}\text { Daily insulin dose/ kg of body weight } \\
\text { (units/kg) }\end{array}$ & $0.51 \pm 0.13^{\#}$ & $0.39 \pm 0.09 * *$ & $0.40 \pm 0.07 * *$ & $0.76 \pm 0.22$ \\
\hline Basal plasma glucose (mmol/l) & $6.12 \pm 1.09$ & $5.48 \pm 1.67$ & $5.91 \pm 1.17$ & $5.15 \pm 0.58$ \\
\hline $\begin{array}{l}\text { Glycated hemoglobin concentration } \\
(\%)\end{array}$ & $7.9 \pm 1.1$ & $7.2 \pm 1.1 *$ & $7.4 \pm 1.4$ & $9.2 \pm 2.1$ \\
\hline Total Serum cholesterol (mmol/l) & $4.96 \pm 0.92$ & $4.74 \pm 1.04$ & $4.47 \pm 1.05$ & $5.07 \pm 0.93$ \\
\hline Serum HDL cholesterol ( $\mathrm{mmol} / \mathrm{l})$ & $1.30 \pm 0.4$ & $1.05 \pm 0.35$ & $1.27 \pm 0.38$ & $1.58 \pm 0.45$ \\
\hline Serum LDL cholesterol (mmol/l) & $3.18 \pm 0.92$ & $3.11 \pm 1.01$ & $2.73 \pm 1.09$ & $3.0 \pm 0.77$ \\
\hline Serum TAG $(\mathrm{mmol} / \mathrm{l})$ & $1.31 \pm 0.38$ & $1.28 \pm 0.43$ & $1.31 \pm 0.64$ & $1.12 \pm 0.31$ \\
\hline Serum uricemia $(\mu \mathrm{mol} / \mathrm{l})$ & $248 \pm 85$ & $452 \pm 99 * *$ & $260 \pm 76$ & $193.9 \pm 40.6$ \\
\hline
\end{tabular}

Significant differences: $* P<0.05$, obese T1DM subjects within the indicated time vs. the same subjects before fasting (ANOVA RM). ** $\mathrm{P}<0.001$, obese T1DM subjects within the indicated time vs. the same subjects before fasting (ANOVA RM). ${ }^{\#} \mathrm{P}<0.05$, obese T1DM subjects before fasting vs. controls (t-test). (a) Basal insulin dose on the seventh day of fasting.

\section{Results}

All patients tolerated the period of fasting. Glycemia during fasting was maintained at $5 \mathrm{mmol} / \mathrm{l}$ by adjustment of the basal insulin dose. There was no severe hypoglycemia in obese T1DM patients during the fasting period. There were seven mild episodes of symptomatic hypoglycemia in the group of obese T1DM patients during the fasting period, which were treated with 10 $20 \mathrm{~g}$ of glucose in liquid form. Clinical and biochemical changes during fasting and LCD period are summarized in Table 1. Obese T1DM patients lost $6.1 \pm 1.1 \mathrm{~kg}$ of body 
weight and $7.3 \pm 2.9 \mathrm{~cm}$ in waist circumference after fasting, and maintained this reduction in body weight and waist circumference after 21 days of low calorie diet. Mean basal insulin dose on the seventh day of fasting and daily insulin dose after 21 days of low calorie diet remained lower than before fasting $(\mathrm{P}<0.001)$. RQ measured by indirect calorimetry before the clamp procedure decreased significantly after fasting and remained significantly lower after 21 days of low calorie diet. $\beta$-Hydroxybutyrate concentration increased significantly during fasting $(0.16 \pm 0.24$ on the first day versus $1.66 \pm 0.75 \mathrm{mmol} / \mathrm{l}$ on the seventh day, $\mathrm{P}<0.001)$. The acid-base balance during fasting was normal. Fasting was accompanied by a transient elevation in serum uricemia $(\mathrm{P}<0.001)$. Plasma free fatty acid concentration in obese T1DM patients before fasting was significantly higher than in controls $(\mathrm{P}<0.05)$ and increased significantly after fasting $(\mathrm{P}<0.001)$. There was a significant decrease in plasma free fatty acid concentration during the clamp procedure in both groups of patients due to hyperinsulinemia (at 120-360 min after fasting, at 180-360 $\mathrm{min}$ before fasting, 21 days after LCD, and in controls) $(\mathrm{P}<0.001)$ (Table 2$)$. There was a significant difference in body fat and relative lean tissue mass between obese T1DM and controls $(\mathrm{P}<0.001)$ and a significant decrease in body fat after fasting and after 21 days of low calorie diet in obese T1DM patients, as measured by bioimpedance spectroscopy $\quad(\mathrm{P}<0.05)$ (Table 3).

Table 2. Plasma free fatty acids in clamp procedure during fasting and LCD period.

\begin{tabular}{lcllc||c}
\hline & $\begin{array}{l}\text { Obese T1DM } \\
(\mathbf{n = 1 4 )}\end{array}$ & Before fasting & After fasting & $\begin{array}{c}\text { After 21 days } \\
\text { of } \mathbf{L C D}\end{array}$ & $\begin{array}{c}\text { Controls } \\
(\mathbf{n}=\mathbf{1 3})\end{array}$ \\
\hline & baseline & $0.51 \pm 0.27^{\#}$ & $1.03 \pm 0.42^{* *}$ & $0.47 \pm 0.21$ & $0.25 \pm 0.17$ \\
& $60 \mathrm{~min}$ & $0.15 \pm 0.12$ & $0.40 \pm 0.26$ & $0.18 \pm 0.07$ & $0.11 \pm 0.01$ \\
Plasma free fatty & $120 \mathrm{~min}$ & $0.11 \pm 0.09$ & $0.34 \pm 0.23$ & $0.12 \pm 0.06$ & $0.09 \pm 0.09$ \\
acids during clamp & $180 \mathrm{~min}$ & $0.10 \pm 0.09$ & $0.16 \pm 0.09$ & $0.08 \pm 0.04$ & $0.06 \pm 0.06$ \\
procedure (mmol/l) & $240 \mathrm{~min}$ & $0.08 \pm 0.06$ & $0.21 \pm 0.12$ & $0.07 \pm 0.05$ & $0.09 \pm 0.12$ \\
& $300 \mathrm{~min}$ & $0.07 \pm 0.06$ & $0.21 \pm 0.11$ & $0.08 \pm 0.05$ & $0.03 \pm 0.05$ \\
& $360 \mathrm{~min}$ & $0.07 \pm 0.06$ & $0.19 \pm 0.11$ & $0.06 \pm 0.05$ & $0.06 \pm 0.07$ \\
\hline
\end{tabular}

Significant differences: $* * P<0.001$, obese T1DM subjects within the indicated time vs. the same subjects before fasting (ANOVA RM). \# $\mathrm{P}<0.05$, obese T1DM subjects before fasting vs. controls (t-test).

Table 3. Changes in body composition during fasting and LCD period measured by bioimpedance spectroscopy.

\begin{tabular}{llll||c}
\hline \multicolumn{1}{c}{$\begin{array}{c}\text { Obese T1DM } \\
\text { (n=14) }\end{array}$} & Before fasting & After fasting & $\begin{array}{c}\text { After 21 days } \\
\text { of } \text { L CD }\end{array}$ & $\begin{array}{c}\text { Controls } \\
(\mathbf{n}=\mathbf{1 3})\end{array}$ \\
\hline Lean tissue mass (kg) & $50.6 \pm 11.5$ & $49.2 \pm 13.6$ & $49.5 \pm 11.1$ & $51.0 \pm 13.5$ \\
Relative lean tissue mass (\%) & $50.1 \pm 7.89^{\#}$ & $52.6 \pm 10.7$ & $52.1 \pm 8.38$ & $72.8 \pm 12.7$ \\
Fat (kg) & $36.9 \pm 4.77^{\#}$ & $33.0 \pm 5.46^{*}$ & $33.3 \pm 5.53^{*}$ & $13.6 \pm 5.29$ \\
Relative fat (\%) & $37.0 \pm 5.31^{\#}$ & $36.0 \pm 7.37$ & $35.4 \pm 5.45$ & $20.1 \pm 8.72$ \\
\hline
\end{tabular}

Significant differences: $* P<0.05$, obese T1DM subjects within the indicated time vs. the same subjects before fasting (ANOVA RM). \# $\mathrm{P}<0.05$, obese T1DM subjects before fasting vs. controls (t-test).

Glucose disposal rates and their components during both phases of hyperinsulinemia, as measured by hyperinsulinemic-euglycemic clamp, are shown in Table 4. Glucose disposal in both phases of the clamp in obese T1DM patients was significantly lower than in controls $(\mathrm{P}<0.05)$. Glucose oxidation in the first phase of the clamp in obese T1DM was significantly lower than in controls $(\mathrm{P}<0.05)$. Non-oxidative glucose disposal in the second phase of the clamp in obese T1DM was significantly lower than in controls $(\mathrm{P}<0.05)$. Fasting 
reduced insulin-mediated glucose consumption in both phases of the clamp $(\mathrm{P}<0.001)$. The reduction in glucose disposal after fasting was caused by a significant reduction in glucose oxidation in both phases of the clamp $(\mathrm{P}<0.001)$. Non-oxidative glucose disposal remained unchanged. Glucose disposal $(\mathrm{M})$ and nonoxidative glucose disposal in both phases of the clamp and glucose oxidation in the second phase of the clamp measured after 21 days of low calorie diet returned to baseline. Glucose oxidation in the first phase of the clamp measured after 21 days of low calorie diet remained lower $(\mathrm{P}<0.05)$. We compared correlations between a relative change in $I R(I R=1 / M)$ measured during both clamp phases (expressed as $\mathrm{M}$ baseline/M starved) and relative to changes in FFA. The change in IR in the first phase of the clamp after fasting and after 21 days of low calorie diet was positively correlated with a change in plasma FFA (Fig. 1). We did not find a significant correlation between the change in IR and change in plasma FFA in the second phase of the clamp.

Table 4. Glucose disposal and its components before and after fasting and LCD period.

\begin{tabular}{|c|c|c|c|c|c|}
\hline & $\begin{array}{l}\text { Obese T1DM } \\
(n=14)\end{array}$ & Before fasting & After fasting & $\begin{array}{l}\text { After } 21 \text { days } \\
\text { of } L C D\end{array}$ & $\begin{array}{c}\text { Controls } \\
(n=13)\end{array}$ \\
\hline \multirow{6}{*}{$\begin{array}{l}\text { Lower insulin } \\
\text { infusion rate } \\
\left(1 \mathrm{mU} \min ^{-1} \mathrm{~kg}^{-1}\right)\end{array}$} & 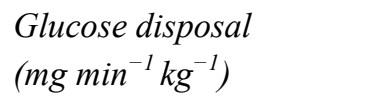 & $5.18 \pm 1.43^{\#}$ & $2.96 \pm 0.49 * *$ & $4.9 \pm 0.97$ & $6.76 \pm 1.43$ \\
\hline & Glucose oxidation & $1.55 \pm 0.64^{\#}$ & $-0.01 \pm 0.56^{* *}$ & $1.20 \pm 0.59 *$ & $2.77 \pm 1.20$ \\
\hline & $\begin{array}{l}\text { Non-oxidative glucose } \\
\text { disposal }\end{array}$ & $3.63 \pm 1.48$ & $3.06 \pm 0.61$ & $3.71 \pm 0.66$ & $3.99 \pm 1.19$ \\
\hline & $\begin{array}{l}\text { Glucose metabolic } \\
\text { clearance rate } \\
\left(\mathrm{ml} \mathrm{min} \mathrm{mg}^{-1}\right)\end{array}$ & $5.54 \pm 1.69^{\#}$ & $3.11 \pm 0.69$ & $5.38 \pm 1.36$ & $7.84 \pm 1.95$ \\
\hline & $\begin{array}{l}\text { Glucose concentration } \\
\text { (mmol/l) }\end{array}$ & $5.19 \pm 0.49$ & $5.36 \pm 0.62$ & $5.16 \pm 0.53$ & $4.86 \pm 0.57$ \\
\hline & $\begin{array}{l}\text { Plasma immunoreactive } \\
\text { insulin (pmol/l) }\end{array}$ & $1002 \pm 710^{\#}$ & $990 \pm 1037$ & $987 \pm 998$ & $400 \pm 207$ \\
\hline \multirow{6}{*}{$\begin{array}{l}\text { Higher insulin } \\
\text { infusion rate } \\
\left(10 \mathrm{mU} \mathrm{min}^{-1} \mathrm{~kg}^{-1}\right)\end{array}$} & $\begin{array}{l}\text { Glucose disposal } \\
\left(\mathrm{mg} \mathrm{min}^{-1} \mathrm{~kg}^{-1}\right)\end{array}$ & $9.69 \pm 1.48^{\#}$ & $6.78 \pm 1.21^{* *}$ & $9.31 \pm 1.16$ & $12.02 \pm 2.16$ \\
\hline & Glucose oxidation & $2.81 \pm 0.52$ & $0.88 \pm 0.98 * *$ & $2.80 \pm 0.67$ & $3.54 \pm 1.17$ \\
\hline & $\begin{array}{l}\text { Non-oxidative glucose } \\
\text { disposal }\end{array}$ & $6.88 \pm 1.44^{\#}$ & $5.94 \pm 0.87$ & $6.51 \pm 1.03$ & $8.48 \pm 1.58$ \\
\hline & $\begin{array}{l}\text { Glucose metabolic } \\
\text { clearance rate } \\
\left(\mathrm{ml} \mathrm{min}^{-1} \mathrm{~kg}^{-1}\right)\end{array}$ & $10.04 \pm 1.57^{\#}$ & $7.63 \pm 1.59$ & $9.91 \pm 1.29$ & $13.25 \pm 2.67$ \\
\hline & $\begin{array}{l}\text { Glucose concentration } \\
\text { (mmol/l) }\end{array}$ & $5.26 \pm 0.34^{\#}$ & $4.99 \pm 0.47$ & $5.23 \pm 0.19$ & $5.06 \pm 0.19$ \\
\hline & $\begin{array}{l}\text { Plasma immunoreactive } \\
\text { insulin (pmol/l) }\end{array}$ & $14946 \pm 5175 \#$ & $16311 \pm 3398$ & $12152 \pm 5051$ & $7918 \pm 2309$ \\
\hline \multicolumn{2}{|c|}{$\begin{array}{l}\text { Indirect calorimetry } R Q \text { before the clamp } \\
\text { procedure }\end{array}$} & $0.84 \pm 0.05$ & $0.78 \pm 0.06^{*}$ & $0.80 \pm 0.06^{*}$ & $0.87 \pm 0.08$ \\
\hline
\end{tabular}

Significant differences: $* P<0.05$, obese T1DM subjects within the indicated time vs. the same subjects before fasting (ANOVA RM). ** $\mathrm{P}<0.001$, obese T1DM subjects within the indicated time vs. the same subjects before fasting (ANOVA RM). ${ }^{\#} \mathrm{P}<0.05$, obese T1DM subjects before fasting vs. controls (t-test). 


\section{(A) after fasting}

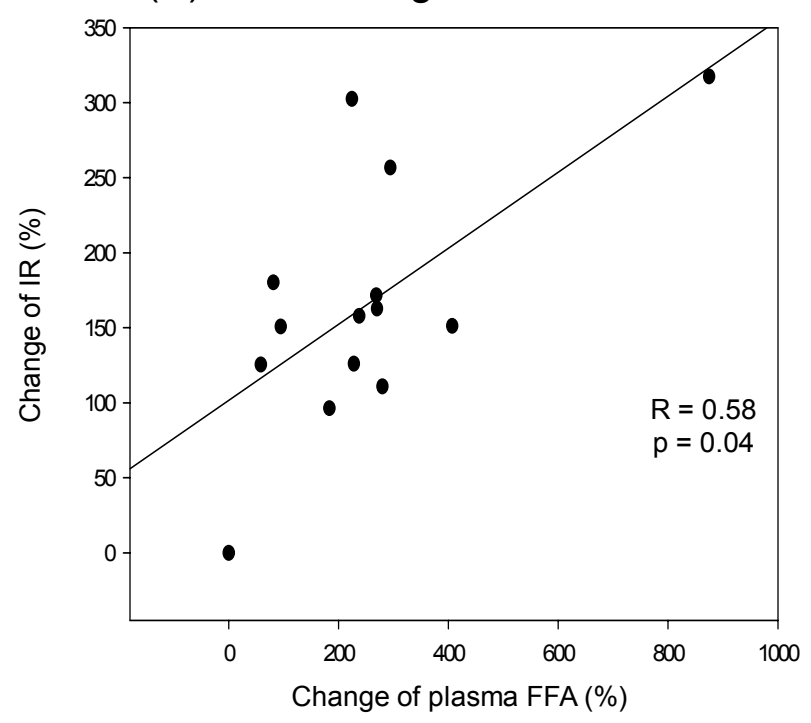

(B) after 21 days of LCD

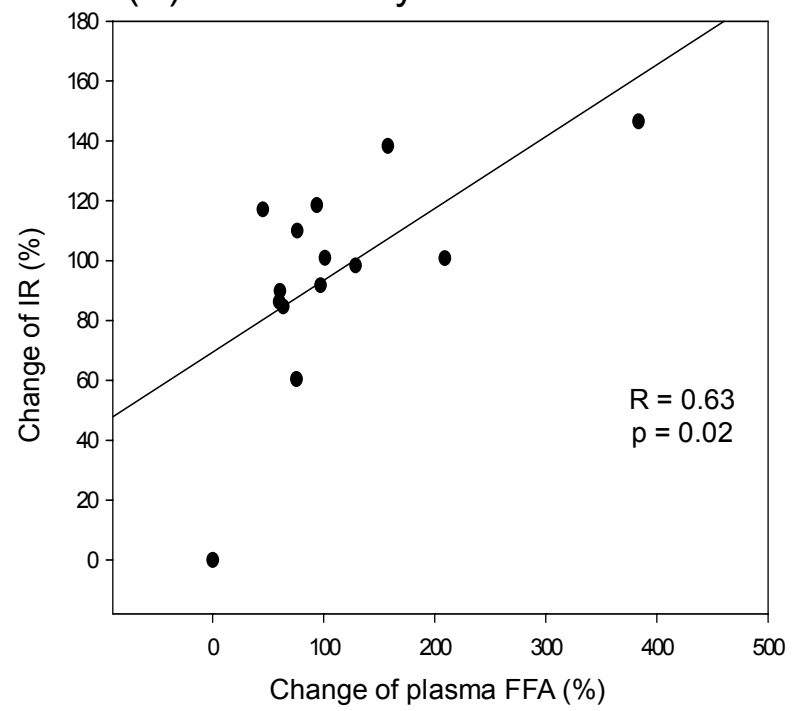

Fig. 1. Relation between a change of insulin resistance (IR) and a change of plasma free fatty acids (FFA) after fasting (A) and after 21 days of $\operatorname{LCD}(\mathbf{B})$.

\section{Discussion}

This study shows that fasting transiently decreases insulin sensitivity in C-peptide-negative obese T1DM patients. This effect of fasting on insulin sensitivity has not been described previously in T1DM patients. The fasting-induced IR returned to baseline after three weeks of low calorie diet. This temporary decrease of insulin sensitivity was caused by reduction of glucose oxidation. This decline in glucose oxidation reflects an adaptation in metabolism to non-stress fasting and is in agreement with previous publications (Awad et al. 2009, Duška et al. 2005, Féry and Balasse 1994, MacDonald et al. 1995). After seven days of fasting, there was an increase in lipid oxidation and stimulated ketogenesis and gluconeogenesis. Contrary to previous studies in fasting T2DM patients, we did not find a decline (Duška et al. 2005) or an increase (Féry and Balasse 1994) in nonoxidative glucose disposal after fasting. Non-oxidative glucose disposal reflected mainly glycogen synthesis in this study. The different length of fasting periods could play a role. In the present study, patients fasted for 7 days, whereas in previous studies, patients fasted for only 60 hours (Duška et al. 2005) or for 4 days (Féry and Balasse 1994). After 7 days of fasting, there is fullystimulated ketogenesis and gluconeogenesis, which was reflected in the low RQ and low basal insulin dose after the fasting period. The calculated zero value of glucose oxidation in the first phase of clamp after fasting (Table 4) was caused by gluconeogenesis. The gluconeogenesis was not suppressed by low insulin infusion rate in the first two hours of the clamp. To suppress fully-stimulated gluconeogenesis after 7 days of fasting the higher insulin infusion rate and longer clamp duration was needed in obese T1DM patients (Miyazaki et al. 2009). Hepatic glucose production was not measured in this study, so the first phase of the clamp with low insulin infusion rate revealed limitations of the indirect calorimetry which was used for calculation of glucose oxidation. When patients stopped fasting and continued body weight reduction by LCD, insulin sensitivity remained the same as at baseline, but total daily insulin dose was lower due to a lower intake of calories and lower body weight. The lower glucose oxidation and lower RQ measured after 21 days of LCD period corresponded to a lower intake of calories. In the group of C-peptide-negative T1DM patients, it was not possible to improve insulin secretion capacity by lowcalorie diet, as was previously described in a group of obese subjects with impaired glucose tolerance (Yoshida et al. 2004). The similar total daily dose of insulin in both groups of T1DM patients (Table 1) can be caused by lower insulin clearance in obese T1DM patients. Insulin clearance in the liver and in the kidney decreases in obesity and IR (Valera Mora et al. 2003). Insulin sensitivity before fasting in the group of obese T1DM patients was lower than in non-obese controls. This was caused by lower glucose oxidation in the first phase of the clamp and lower non-oxidative glucose disposal in the second phase of the clamp in the group of obese T1DM patients before fasting. The lower glucose 
oxidation can be explained by higher baseline concentrations of FFA in obese T1DM, which decreased during the clamp procedure to FFA concentrations similar to those in non-obese controls (Table 2). The lower nonoxidative glucose disposal can be explained by a higher amount of fat tissue in obese T1DM with a lower rate of glycogen synthesis per kilogram of body weight compared with non-obese controls. The finding of higher baseline IR with lower glucose oxidation and higher FFA concentration in the group of obese T1DM patients is important because previous studies have described an association of higher IR with increased subsequent risk of both micro- and macrovascular complications in T1DM patients (De Block et al. 2005, Chillarón et al. 2009, Kilpatrick et al. 2007, Yip et al. 1993, Pambianco et al. 2007). The insulin sensitivity was not diminished during fasting as a result of acidosis - the acid-base balance was normal. $\beta$-Hydroxybutyrate concentration measured in this study did not indicate ketoacidosis. In a previous study $\beta$-hydroxybutyrate values above $3 \mathrm{mmol} / 1$ indicated ketoacidosis (Wallace et al. 2001).

An additional priority of this study was to explore the use of controlled fasting with subsequent home low calorie diet as a therapeutic tool in the management of obesity in T1DM patients. In C-peptidenegative obese T1DM patients, we simulated physiologic non-stress fasting by giving only a basal insulin dose during the fasting. All patients tolerated the 7 days of fasting well without complications. The body weight reduction which was achieved by fasting was caused by a decrease in body fat without a decrease in lean tissue mass as we confirmed by bioimpedance spectroscopy technique. The body weight reduction achieved during the fasting may stimulate further body weight reduction and solve previous unsuccessful attempts at body weight reduction. The initial body weight reduction can have significant positive psychological effects in obese T1DM patients.

In conclusion we confirmed that insulin sensitivity, measured as the rate of insulin-mediated glucose disposal, decreases transiently during fasting in obese T1DM individuals, as was previously described in a group of obese T2DM patients and in a group of obese non-diabetic patients. This decrease is only a temporary adaptation of metabolism to non-stress fasting, and insulin sensitivity returns to baseline after a LCD period. The changes in plasma FFA probably play a role (Duška et al. 2007, Johnson et al. 2006, Muniyappa et al. 2008, Norrelund et al. 2003, Petersen and Shulman 2006, Salgin et al. 2009, Sprangers et al. 2001). In the presented study we found a positive relationship between the change in insulin resistance and change in plasma FFA concentrations throughout the group of 14 obese T1DM patients. This relationship between IR and FFA was previously described in obese T2DM (Duška et al. 2005). To confirm this relationship between IR and FFA further studies with larger groups of obese T1DM patients are needed. Because obesity can modify the initial T1DM phenotype and accelerate the presentation of cardiovascular risk factors, the approach to obese T1DM patients should be the same as for T2DM. The multifactorial therapy should include among others an early and intensive treatment of obesity. Controlled fasting with subsequent home low calorie diet can be used as a safe therapeutic tool in the management of obesity in T1DM patients.

\section{Conflict of Interest}

There is no conflict of interest.

\section{Acknowledgements}

This work was supported by research project IGA No. NT/12287-5 from the Ministry of Health of the Czech Republic.

\section{References}

ALBERTI KGMM, ECKEL RH, GRUNDY SM, ZIMMET PZ, CLEEMAN JI, DONATO KA, FRUCHART JC, JAMES WPT, LORIA CM, SMITH SC Jr: Harmonizing the metabolic syndrome. Circulation 120: 1640-1645, 2009.

ALDHAHI W, HAMDY O: Adipokines, inflammation and the endothelium in diabetes. Curr Diab Rep 3: 293-298, 2003.

ALEXANDER CM, LANDSMAN PB, TEUTSCH SM, HAFFNER SM; THIRD NATIONAL HEALTH AND NUTRITION EXAMINATION SURVEY (NHANES III); NATIONAL CHOLESTEROL EDUCATION PROGRAM (NCEP): NCEP-defined metabolic syndrome, diabetes, and prevalence of coronary heart disease among NHANES III participants age 50 years and older. Diabetes 52: 1210-1214, 2003. 
AWAD S, CONSTANTIN-TEODOSIU D, MACDONALD IA, LOBO DN: Short-term starvation and mitochondrial dysfunction - a possible mechanism leading to postoperative insulin resistance. Clin Nutr 28: 497-509, 2009.

CHILLARÓN JJ, GODAY A, FLORES-LE-ROUX JA, BENAIGES D, CARRERA MJ, PUIG J, CANO-PÉREZ JF, PEDRO-BOTET J: Estimated glucose disposal rate in assessment of the metabolic syndrome and microvascular complications in patients with type 1 diabetes. J Clin Endocrinol Metab 94: 3530-3534, 2009.

CHOKKALINGAM K, TSINTZAS K, NORTON L, JEWELL K, MACDONALD IA, MANSELL PI: Exercise under hyperinsulinaemic conditions increases whole-body glucose disposal without affecting muscle glycogen utilisation in type 1 diabetes. Diabetologia 50: 414-421, 2007.

CONWAY B, MILLER RG, COSTACOU T, FRIED L, KELSEY S, EVANS RW, ORCHARD TJ: Temporal patterns in overweight and obesity in Type 1 diabetes. Diabet Med 27: 398-404, 2010.

DCCT RESEARCH GROUP: Adverse events and their association with treatment regimens in the Diabetes Control and Complications Trial. Diabetes Care 18: 1415-1427, 1995.

DE BLOCK CEM, DE LEEUW IH, VAN GAAL LF: Impact of overweight on chronic microvascular complications in type 1 diabetic patients. Diabetes Care 28: 1649-1655, 2005.

DEFRONZO RA, TOBIN JD, ANDRES R: Glucose clamp technique: a method for quantifying insulin secretion and resistance. Am J Physiol 237: E214-E223, 1979.

DUŠKA F, ANDĚL M, KUBĚNA A, MACDONALD IA: Effects of acute starvation on insulin resistance in obese patients with and without type 2 diabetes mellitus. Clin Nutr 24: 1056-1064, 2005.

DUŠKA F, TŮMA P, MOKREJŠ P, KUBĚNA A, ANDĚL M: Analysis of factors influencing nitrogen balance during acute starvation in obese subject with and without type 2 diabetes. Clin Nutr 26: 552-558, 2007.

FERRANNINI E: The theoretical bases of indirect calorimetry: a review. Metabolism 37: 287-301, 1988.

FÉRY F, BALASSE EO: Glucose metabolism during the starved-to-fed transition in obese patients with NIDDM. Diabetes 43: 1418-1425, 1994.

JACOBSEN IB, HENRIKSEN JE, BECK-NIELSEN H: The effect of metformin in overweight patients with type 1 diabetes and poor metabolic control. Basic Clin Pharmacol Toxicol 105: 145-149, 2009.

JOHNSON NA, STANNARD SR, ROWLANDS DS, CHAPMAN PG, THOMPSON CH, O'CONNOR H, SACHINWALLA T, THOMPSON MW: Effect of short-term starvation versus high-fat diet on intramyocellular triglyceride accumulation and insulin resistance in physically fit men. Exp Physiol 91: 693703, 2006.

KEMMER FW: Prevention of hypoglycemia during exercise in type I diabetes. Diabetes Care 15: 1732-1735, 1992.

KILPATRICK ES, RIGBY AS, ATKIN SL: Insulin resistance, the metabolic syndrome, and complication risk in type 1 diabetes: "double diabetes" in the Diabetes Control and Complications Trial. Diabetes Care 30: 707-712, 2007.

LIBMAN IM, PIETROPAOLO M, ARSLANIAN SA, LAPORTE RE, BECKER DJ: Changing prevalence of overweight children and adolescents at onset of insulin-treated diabetes. Diabetes Care 26: 2871-2875, 2003.

MACDONALD IA, WEBBER J: Feeding, fasting and starvation: factors affecting fuel utilization. Proc Nutr Soc 54: 267-274, 1995.

MCGILL M, MOLYNEAUX L, TWIGG SM, YUE DK: The metabolic syndrome in type 1 diabetes: does it exist and does it matter? J Diabetes Complications 22: 18-23, 2008.

MIYAZAKI Y, DEFRONZO RA: Visceral fat dominant distribution in male type 2 diabetic patients is closely related to hepatic insulin resistance, irrespective of body type. Cardiovasc Diabetol 8: 44, 2009.

MUNIYAPPA R, LEE S, CHEN H, QUON JM: Current approaches for assessing insulin sensitivity and resistance in vivo: advantages, limitations and appropriate usage. Am J Physiol 294: E15-E26, 2008.

NORRELUND H, NAIR KS, NIELSEN S, FRYSTYK J, IVARSEN P, JORGENSEN JOL, CHRISTIANSEN JS, MOLLER N: The decisive role of free fatty acids for protein conservation during fasting in humans with and without growth hormone. J Clin Endocrinol Metab 88: 4371-4378, 2003.

PAMBIANCO G, COSTACOU T, ORCHARD TJ: The prediction of major outcomes of type 1 diabetes: a 12-year prospective evaluation of three separate definitions of the metabolic syndrome and their components and estimated glucose disposal rate: the Pittsburgh Epidemiology of Diabetes Complications Study experience. Diabetes Care 30: 1248-1254, 2007.

PETERSEN KF, SHULMAN GI: Etiology of insulin resistance. Am J Med 119 (Suppl 1): S10-S16, 2006. 
SALGIN B, MARCOVECCHIO ML, WILLIAMS RM, JACKSON SJ, BLUCK LJ, HUMPHREYS SM, ACERINI CL, DUNGER DB: Effects of growth hormone and free fatty acids on insulin sensitivity in patients with type 1 diabetes. J Clin Endocrinol Metab 94: 3297-3305, 2009.

SPRANGERS F, ROMIJN JA, ENDERT E, ACKERMANS MT, SAUERWEIN HP: The role of free fatty acids (FFA) in the regulation of intrahepatic fluxes of glucose and glycogen metabolism during short-term starvation in healthy volunteers. Clin Nutr 20: 177-179, 2001.

SZADKOWSKA A, PIETRZAK I, SZLAWSKA J, KOZERA A, GADZICKA A, MLYNARSKI W: Abdominal obesity, metabolic syndrome in type 1 diabetic children and adolescents. Pediatr Endocrinol Diabetes Metab 15: 233-239, 2009.

VALERA MORA ME, SCARFONE A, CALVANI M, GRECO AV, MINGRONE G: Insulin clearance in obesity. $J$ Am Coll Nutr 22: 487-493, 2003.

VAN VLIET M, VAN DER HEYDEN JC, DIAMANT M, VON ROSENSTIEL IA, SCHINDHELM RK, AANSTOOT HJ, VEEZE HJ: Overweight is highly prevalent in children with type 1 diabetes and associates with cardiometabolic risk. J Pediatr 156: 923-929, 2010.

WALLACE TM, MESTON NM, GARDNER SG, MATTHEWS DR: The hospital and home use of a 30-second handheld blood ketone meter: guidelines for clinical practice. Diabet Med 18: 640-645, 2001.

WILKIN TJ: The accelerator hypothesis: weight gain as the missing link between Type I and Type II diabetes. Diabetologia 44: 914-922, 2001.

YIP J, MATTOCK MB, MOROCUTTI A, SETHI M, TREVISAN R, VIBERTI G: Insulin resistance in insulindependent diabetic patients with microalbuminuria. Lancet 342: 883-887, 1993.

YOSHIDA Y, HASHIMOTO N, TOKUYAMA Y, KITAGAWA H, TAKAHASHI K, YAGUI K, KANATSUKA A, BUJO H, HIGURASHI M, MIYAZAWA S, YOSHIDA S, SAITO Y: Effects of weight loss in obese subjects with normal fasting plasma glucose or impaired glucose tolerance on insulin release and insulin resistance according to a minimal model analysis. Metabolism 53: 1095-1100, 2004. 